\title{
LEMBAR KERJA INSTRUKSI KONSEPTUAL BERBASIS PHET: MENGEMBANGKAN BAHAN AJAR UNTUK MENGKONSTRUKSI KONSEP SISWA PADA EFEK FOTOLISTRIK
}

\author{
Ardian Asyhari ${ }^{1}$ Irwandani $^{2}$, Herli Candra Saputra ${ }^{3}$ \\ ${ }^{1}$ IAIN Raden Intan Lampung; ardianasyhari@radenintan.ac.id \\ 1,2Program Studi Pendidikan Fisika, IAIN Raden Intan Lampung, Bandar Lampung \\ ${ }^{3}$ SMA Negeri 6 Bandar Lampung
}

Diterima: 15 Agustus 2016. Disetujui: 12 Oktober 2016. Dipublikasikan: Oktober 2016

\begin{abstract}
This research focuses on developing a conceptual instruction worksheet on the material of the photoelectric effect for high school students. This research method is Design Research that produces products in the form of worksheets for students to construct the concept about photoelectric effect, so as to assist students in understanding the influence of the wavelength of the photoelectric effect and understand the influence of the type of metal used to the wavelength when the photoelectric effect occurs. After going through the validation experts who assess the content and the interface, then the products are developed tested to the user to determine the respons. By teachers and students, the products gain value with good criteria and otherwise practical for use in the classroom, also make students and teachers interesting with the product.
\end{abstract}

\begin{abstract}
Abstrak: Penelitian ini berfokus untuk mengembangkan lembar kerja instruksi konseptual pada materi efek fotolistrik untuk siswa SMA. Metode penelitian ini adalah Design Research yang menghasilkan produk berupa lembar kerja untuk mengkonstruksi konsep siswa terhadap efek fotolistrik, sehingga dapat membantu siswa dalam memahami pengaruh panjang gelombang terhadap efek fotolistrik dan memahami pengaruh jenis logam yang digunakan terhadap panjang gelombang saat efek fotolistrik terjadi. Setelah melalui validasi ahli yang menilai isi dan antarmuka, kemudian produk yang dikembangkan diujikan kepada pengguna untuk mengetahui respons kepraktisan dan kemenarikkan. Oleh guru dan siswa, produk mendapatkan nilai dengan kriteria baik, dinyatakan praktis untuk digunakan pada pembelajaran, dan menarik minat guru dan juga siswa.
\end{abstract}

(C) 2016 Pendidikan Fisika, FTK IAIN Raden Intan Lampung

Kata kunci: efek fotolistrik, instruksi konseptual, lembar kerja, PhET

\section{PENDAHULUAN}

Pembelajaran fisika selama ini sering disajikan sebagai kumpulan rumus dan persamaan yang merupakan bentuk penyederhanaan dari realitas (Wegener, McIntyre, \& McGrath, 2012) atau yang sering kita kenal sebagai pembelajaran tradisional. Pembelajaran tradisional yang dilakukan oleh guru selama ini masih sering menggunakan bahan ajar yang cukup sulit untuk di akses di setiap waktu dan di setiap tempat (Astra, Nasbey, \& Nugraha, 2015).

Penelitian tentang inovasi dalam pembelajaran fisika akhir-akhir ini, menekankan pada kegiatan pembelajaran yang berpusat pada siswa (Ekmekci \& Gulacar, 2015) sehingga pembelajaran tradisional dirasakan tidak relevan lagi saat ini. Tentunya dalam membelajarkan fisika, guru memerlukan visualisasi sebagai cara yang tepat untuk memberikan pemahaman kepada siswa, khususnya pada materi fisika kuantum.

Karena konsep fisika kuantum yang bersifat abstrak dan tidak terlihat, maka dibutuhkan metode yang tepat untuk memvisualisasikannya agar terhindar dari misksonsepsi (Mursalin, 2013). Sebagai cara yang tepat adalah dengan menggunakan pembelajaran fisika kuantum dengan laboratorium virtual. 
Laboratorium virtual menyediakan banyak kelebihan untuk membelajarkan fisika kuantum, selain aman dan dapat dilakukan dimanapun, hal lain yang menjadi kelebihan adalah faktor efektivitas dalam proses dan hasil (Garrett \& McMahon, 2013; Ekmekci \& Gulacar, 2015; Wieman, K, Perkins, \& Adams, 2008). Penggunaan virtual lab dalam pembelajaran fisika kuantum menawarkan keuntungan menarik, yaitu dengan pendekatan yang lebih konseptual (Dede, Salzman, Loftin, \& Sprague, 1999; Saregar, 2016; Suhandi, Sinaga, Kaniawati, \& Suhendi, 2009). Selain itu, laboratorium virtual juga dapat diberdayakan untuk mengembangkan keterampilan mengamati, menafsirkan, meramalkan, dan mengkomunikasikan (Setiadi \& Muflika, 2012).

Selain itu, laboratorium virtual juga dapat membantu siswa mencapai tiga tujuan pembelajaran, yaitu (1) untuk menghubungkan pengetahuan prosedural dalam bentuk formula matematika dan kenyataan aslinya; (2) untuk membantu siswa mengembangkan pengetahuan prosedural dan keterampilan jadi mereka tidak hanya belajar bagaimana melakukan prosedur percobaan tapi juga kapan prosedur tersebut dapat berlaku; (3) untuk membantu siswa memahami penerapan pengetahuan mereka dalam dunia nyata (Wang \& Woo, 2007).

Banyak laman yang menyediakan fasilitas berupa unduhan aplikasi laboratorium virtual, dan masing-masing memiliki kelebihan dan kekurangan. Pada penelitian ini digunakan Physics Education Technology (PhET) Interactive Simulations sebagai aplikasi laboratorium virtualnya. Aplikasi ini memiliki banyak animasi, interaktif, dan dikembangkan seperti permainan yang dapat memungkinkan siswa bereksplorasi sambil bermain. Selain itu PhET juga menekankan hubungan antara fenomena kehidupan nyata dan ilmu yang mendasarinya yang diungkapkan dalam model visual dan konseptual dengan pendekatan berbasis penelitian yang mendukung keterlibatan siswa sehingga membantu mereka untuk memahami konsep fisika (Perkins, et al., 2006; Podolefsky, Perkins, \& Adams, 2010).

PhET Interactive Simulation di desain sangat baik sebagai program yang dapat membantu siswa dalam proses pembelajaran baik di kelas maupun di laboratorium. Siswa juga dapat belajar untuk mengoperasikan peralatan virtual di kelas (di luar laboratorium) sehingga secara signifikan dapat membantu mereka untuk memperkecil kesalahan penggunaan alat yang asli pada laboratorium (Waller \& Foster, 2000).

Penggunaan PhET dalam pembelajaran sebaiknya dikombinasikan dengan bahan ajar lainnya, sehingga pemahaman siswa terkait dengan materi pembelajaran akan lebih baik. Perkins, et al. (2006) menyarankan agar penggunaan PhET sebaiknya diikuti dengan peer-instruction sehingga pembelajaran dapat terarah. Selain itu, guru juga dapat memberikan penugasan di rumah bagi para siswanya untuk lebih sering dalam berinteraksi dengan PhET. Hal ini agar siswa dapat menemukan, menjelaskan, atau mengkonstruksi alasan dan pendapat tentang pentingnya konsep fisika dalam keseharian mereka.

Penjelasan yang telah ditampilkan menunjukkan bahwa penggunaan laboratorium virtual penting bagi proses pembelajaran fisika, sehingga tujuan dari penelitian ini mengerucut pada pembuatan lembar kerja instruksi konseptual pada pokok bahasan efek foto listrik.

\section{LANDASAN TEORI}

Pada penelitian ini, penggunaan simulasi yang berasal dari aplikasi komputer (PhET) akan diterapkan pada pembelajaran dengan berbantukan lembar kerja instruksi konseptual, sehingga diharapkan dapat menghadirkan proses pembelajaran yang bermakna dan 
terstruktur dalam membangun konsep siswa tentang materi efek foto listrik.

Setidaknya ada tujuh hal yang harus diperhatikan sebelum menggunakan teknologi virtual untuk membantu proses pembelajaran (Chen, et al., 2012):

1) Guru meminta siswa untuk mencari tentang: menjelajahi, semakin akrab dengan fenomena atau benda.

2) Guru meminta siswa untuk mencari informasi: membaca tujuan, mengevaluasi informasi.

3) Guru membantu siswa untuk bertanya dan memurnikan pertanyaan: membuat prediksi atau hipotesis.

4) Guru membimbing siswa dalam perencanaan dan merancang investigasi: merancang prosedur eksperimen, mengidentifikasi variabel secara operasional, pengendalian dan memanipulasi variabel.

5) Melaksanakan prosedur: merakit peralatan laboratorium virtualnya, menindaklanjuti prosedur, melacak ide-ide, membuat pengamatan, mengumpulkan data.

6) Menyusun data: menganalisis, memvisualisasikan data, menciptakan model-model data, membangun penjelasan ilmiah, membuat kesimpulan.

7) Memberitahukan Mengkomunikasikan berbicara kepada orang lain, mempresentasikan ide-ide, menerima umpan balik.

Ketujuh hal tersebut akan diperhatikan dalam pembuatan lembar kerja pada penelitian ini.

Selanjutnya, Chen, et al. (2012) juga menjelaskan tentang 4 dimensi dalam memandang penggunaan teknologi dalam pembelajaran:

1) Mendukung aktivitas pembelajaran.

2) Mendukung untuk inkuiri terbuka.

3) Sebagai cara untuk melaksanakan.
4) Sebagai cara untuk mencapai tujuan pembelajaran.

Tujuan penggunaan PhET dalam pembelajaran fisika kuantum yaitu meningkatkan keterlibatan siswa dan membuat pembelajaran semakin menarik. Pada pokok bahasan efek foto listrik, simulasi yang disajikan oleh PhET sangat baik, karena dapat membantu siswa dalam memahami elektron, foton, dan atom. Sehingga siswa dapat terlibat secara mendalam seperti melakukan eksperimen sebenarnya dan dapat mengobservasi efek fotolistrik lebih baik daripada melakukannya pada laboratorium riil (McKagan, et al., 2008).

Potensi kognitif yang terdapat dalam simulasi PhET, disajikan dalam bentuk analogi-analogi yang dalam penerapannya pada proses pembelajaran haruslah dibantu dengan bahan ajar lain, yang dalam penelitian ini akan digunakan lembar kerja instruksi konseptual. Lembar kerja instruksi konseptual adalah bahan ajar yang disusun dengan sistematis berdasarkan langkah - langkah pembelajaran konsep instruksional. Sehingga pengetahuan siswa terhadap konsep efek foto listrik dapat terkonstruksi dengan baik.

Pembelajaran dengan instruksi konseptual memiliki 4 ciri utama, yaitu berfokus pada segi konseptual, mengutamakan interaksi kelas, menggunakan bahan ajar berbasis penelitian, dan menggunakan teks instruksi (Savinainen \& Viiri, 2008; Sumargo \& Yuanita, 2014). Penggunaan media simulasi virtual dengan lembar kerja instruksi konseptual dapat memvisualkan model mekanisme fisis dari suatu fenomena hingga ke tataran mikro yang tidak mungkin dilakukan dengan menggunakan alat peraga riil. Visualisasi perilaku mikroskopis dari suatu fenomena dapat membantu siswa dalam mengonstruksi konsepsinya, sehingga akan terhindar dari kekeliruan konsep. Media simulasi dapat digunakan 
juga untuk menggambarkan konsepkonsep yang abstrak yang tidak dapat ditunjukkan dengan alat-alat peraga (alat demonstrasi). Alat demonstrasi hanya bisa menunjukkan gejala fisis dari suatu fenomena tetapi tidak mampu menunjukkan bagaimana besaran-besaran fisis yang terkait fenomena saling berinteraksi sehingga muncul gejala fisis seperti yang diamati (Suhandi, Sinaga, Kaniawati, \& Suhendi, 2009).

Keunggulan penggunaan simulasi dalam pembelajaran dan praktikum sebaiknya tidak dijadikan alasan untuk menggantikan peran laboratorium riil (Podolefsky, Perkins, \& Adams, 2010).

\section{METODE}

Penelitian ini menggunakan metode Design Research. Menurut Plomp (2007) design research adalah penelitian yang mendesain atau mengembangkan sebuah intervensi dalam pembelajaran, seperti program aplikasi, strategi pembelajaran, bahan ajar, produk dan sistem, dengan tujuan untuk menyelesaikan permasalahan pendidikan yang kompleks, serta untuk memperkaya pengetahuan kita tentang berbagai macam karakteristik intervensi dan proses yang kita tempuh dalam mendesain dan mengembangkan bentukbentuk intervensi tadi.

Model umum dari design reseach disajikan pada Gambar 1. Model ini mengilustrasikan dengan jelas bahwa pendekatan berturut dari pengembangan produk praktis atau yang kita sebut sebagai intervensi sangat berkaitan dengan prinsip-prinsip dalam mendesain produk (Plomp, 2007).

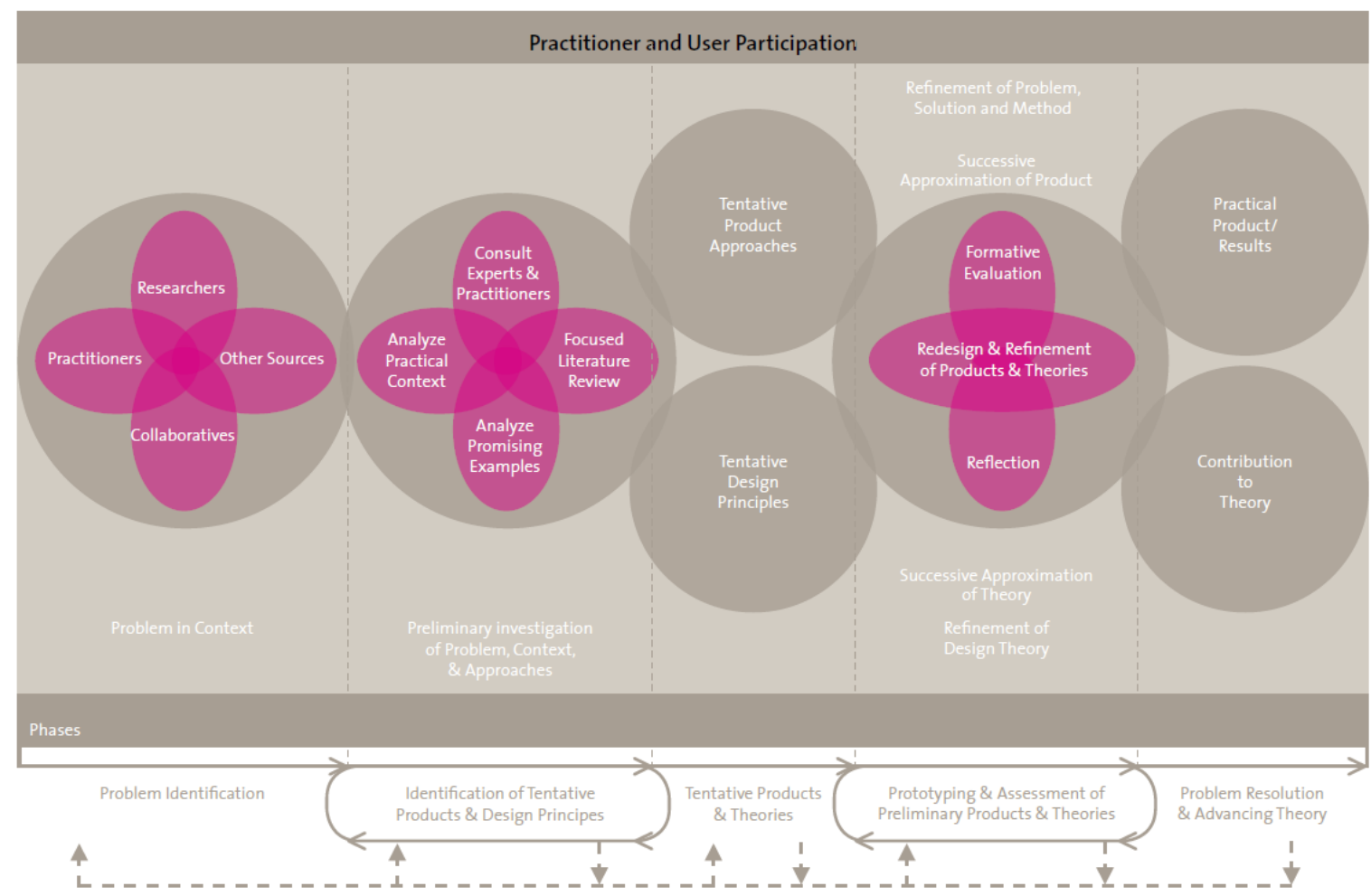

Gambar 1. Model Umum Design Research (Wademan (2005) dalam Plomp, (2007))

Model tersebut perlu kita adaptasikan dengan membuat langkah-langkah yang lebih mewakili fokus kita dalam design research ini. Langkah-langkah yang akan ditempuh dapat dilihat pada Tabel 1.
Subjek penelitian ini adalah siswa kelas XII $(n=97)$ dan guru fisika $(n=6)$ pada SMA Negeri 1 Rumbia Lampung Tengah, SMA Negeri 6 Bandar Lampung, dan SMA Negeri 13 Bandar Lampung. Instrumen yang digunakan 
pada penelitian ini yaitu instrumen evaluasi produk oleh ahli dan instrumen respons oleh pengguna (guru dan siswa).
Instrumen evaluasi ahli dan pengguna terdiri dari validasi isi (content) dan antarmuka (interface).

Tabel 1. Langkah-langkah Design Research (Plomp, 2007)

\begin{tabular}{lll}
\hline No. & Langkah-langkah & Hal-hal yang akan dilakukan \\
\hline 1 & Preliminary research & - Analisis kebutuhan \\
& & - Analisis konteks \\
& - Meninjau literatur \\
& - Mengembangkan konsep \\
& - Membuat blueprint dari produk \\
& - Mendesain produk* \\
& Prototyping stage & Mengevaluasi produk melalui penilaian ahli* \\
& & (*merupakan langkah berulang atau \\
& & microcycle) \\
\hline 3 & Assesment phase & Mengevaluasi produk untuk mengetahui apakah \\
& & pengguna (guru dan siswa) mendapatkan \\
& kepraktisan dan tertarik pada produk sehingga \\
& akan menerapkannya dalam pembelajaran. \\
\hline
\end{tabular}

Validasi ahli dilakukan kepada 2 orang ahli media (AM) dan 2 orang ahli isi (AI) materi fisika efek fotolistrik. Komponen validasi isi digunakan untuk mengetahui relevansi konsep dan evaluasi, keakuratan konsep, teknik penyajian, ilustrasi, dan kejelasan isi; sedangkan untuk validasi antarmuka digunakan untuk mengetahui penilaian ahli terhadap desain produk, keterbacaan, ilustrasi, dan penggunaan bahasa. Kemudian data dinilai dengan skala penilaian dengan skala 4 (Astra, Nasbey, \& Nugraha, 2015; Asyhari \& Hartati, 2015). Instrumen pengguna berupa lembar respons terhadap produk pada aspek kemenarikan dan kepraktisan.

\section{HASIL DAN PEMBAHASAN}

Hasil dari penelitian ini akan disajikan dan dibahas sesuai dengan langkah-langkah yang telah ditetapkan pada Tabel 1. Pada langkah preliminary research dihasilkan blueprint dari produk yang akan dikembangkan sesuai dengan analisis kebutuhan, konteks, literatur, dan konsep yang telah dianalisis.
Hasil dari penelitian ini akan disajikan dan dibahas sesuai dengan langkah-langkah yang telah ditetapkan pada Tabel 1. Pada langkah preliminary research dihasilkan blueprint dari produk yang akan dikembangkan sesuai dengan analisis kebutuhan, konteks, literatur, dan konsep yang telah dianalisis.

Blueprint yang dihasilkan pada tahap ini yaitu berupa hal-hal yang perlu diperhatikan untuk membuat prototipe produk pada tahap selanjutnya. Hal-hal tersebut adalah:

1) Desain; desain dari lembar kerja akan dibuat dengan format 1 kolom dengan warna dan background yang akan kontras dengan tulisan dan gambar.

2) Tata letak; penjelasan instruksi, yaitu berupa gambar dan tulisan dibuat saling berdekatan sehingga dapat memperjelas siswa. Disediakan tempat agar siswa dapat menggambarkan hasil pengamatannya.

3) Isi; tujuan pembelajaran, teori singkat, cara penggunaan, instruksi kegiatan pembuktian, analisa hasil 
pengamatan,

kesimpulan, dan tugas.

4) Tujuan pembelajaran; (1) Siswa dapat memahami pengaruh panjang gelombang terhadap efek foto listrik. (2) Siswa dapat memahami pengaruh jenis logam yang digunakan terhadap panjang gelombang saat efek fotolistrik terjadi.
Hasil dari prototyping stage yaitu desain prototipe yang perlu dievaluasi (validasi) oleh ahli. Sebagai proses micro-cycle, validasi dan revisi dilakukan sebanyak dua kali sampai produk dapat dipergunakan. Data hasil dari microcycle validasi dan saran perbaikan produk pada aspek isi dapat dilihat pada Gambar 2 dan Tabel 2.

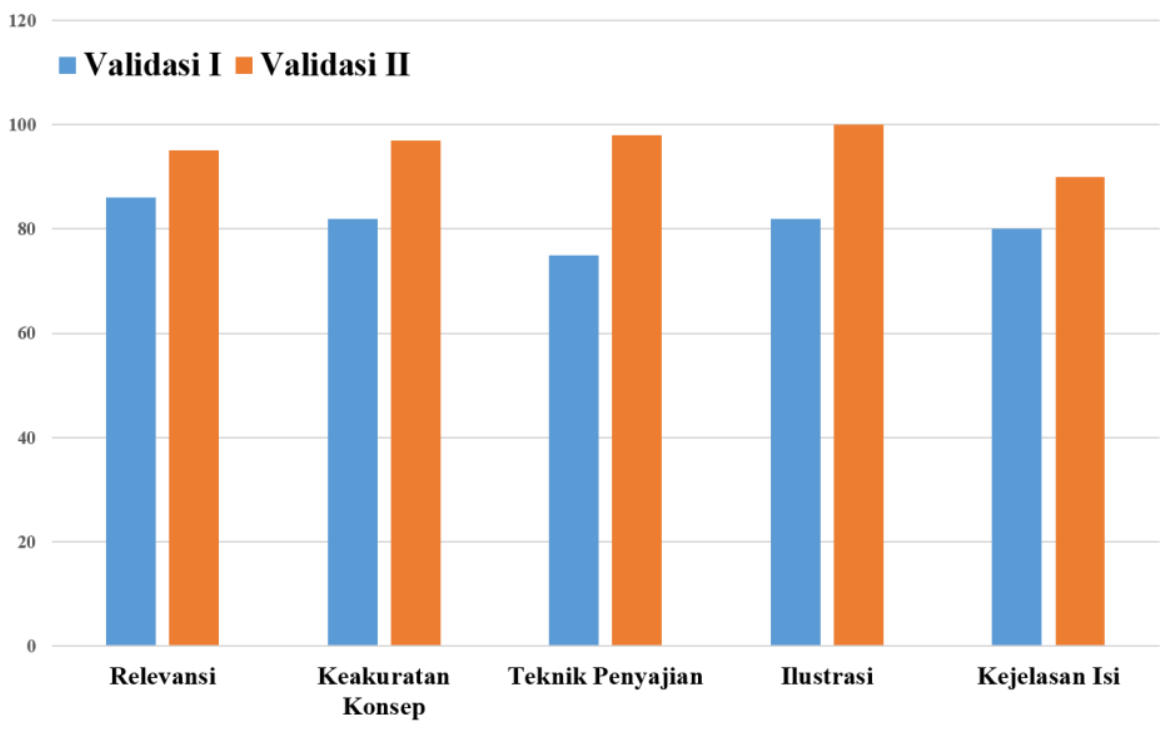

Gambar 2. Hasil Validasi Ahli Materi (Content) Tahap 1 dan 2

Tabel 2. Saran Perbaikan Ahli Materi Tahap 1 dan 2

\section{Saran Perbaikan Isi Tahap 1}

\begin{tabular}{|c|c|}
\hline AI 1 & $\begin{array}{l}\text { a. Perbaiki penulisan notasi dan simbol matematisnya } \\
\text { b. Sesuaikan penulisan persamaan (vektor atau skalar) } \\
\text { c. Teknik penyajian belum memenuhi pembelajaran instruksi } \\
\text { konseptual }\end{array}$ \\
\hline AI 2 & $\begin{array}{l}\text { a. Lebih baik jika menerangkan materi fisika diikuti bentuk } \\
\text { persamaan } \\
\text { b. Instruksi belum begitu memenuhi pembelajaran konsep } \\
\text { instruksional } \\
\text { c. Materi yang belum sesuai }\end{array}$ \\
\hline
\end{tabular}

\section{Saran Perbaikan Isi Tahap 2}

\begin{tabular}{ll}
\hline AI 1 & Produk sudah bisa diujicoba ke tahap selanjutnya \\
\hline AI 2 & Produk sudah bisa diujicoba ke tahap selanjutnya \\
\hline
\end{tabular}

Validasi isi dilakukan dengan mengajukan sebanyak 17 pertanyaan kepada ahli terkait dengan relevansi konsep dan evaluasi, keakuratan konsep, teknik penyajian, ilustrasi, dan kejelasan isi. Gambar 2 menunjukkan bahwa pada validasi tahap I, produk yang dikembangkan masih terdapat kekurangan, sehingga saran perbaikan 
yang ditampilkan pada Tabel 2 merupakan saran untuk perbaikannya.

Pada tahap I, aspek yang dikomentari adalah terkait dengan teknik penyajian (75\%); yaitu produk disajikan belum baik dalam pembelajaran konsep instruksional. Setelah diperbaiki sesuai dengan saran, skor untuk aspek penyajian diperoleh $98 \%$.

Aspek relevansi materi dan evaluasi pada tahap I mendapatkan skor sebesar $86 \%$, aspek keakuratan konsep, mendapatkan skor sebesar $82 \%$, aspek ilustrasi $82 \%$, dan kejelasan isi sebesar $80 \%$. Saran perbaikan yang muncul untuk keempat aspek ini adalah perihal pemakaian bahasa pada soal dan instruksi yang kurang tepat, sehingga perbaikan dilakukan sesuai saran. Prototipe yang telah diperbaiki, selanjutnya di validasi ulang. Untuk aspek relevansi materi dan evaluasi pada tahap II didapatkan skor 95\%, keakuratan konsep mendapatkan skor
$97 \%$, ilustrasi mendapatkan skor $100 \%$, dan kejelasan isi mendapatkan skor $90 \%$.

Prototipe yang kontennya telah tervalidasi, kemudian diajukan kembali kepada ahli media untuk mengevaluasi antarmukanya, aspek-aspek yang di validasi adalah desain produk, keterbacaan, ilustrasi, dan penggunaan bahasa yang total indikatornya adalah 37 buah. Data hasil dari microcycle validasi dan saran perbaikan produk pada aspek antarmuka dapat dilihat pada Gambar 3 dan Tabel 3.

Pada tahap I, aspek yang dikomentari adalah terkait dengan penggunaan bahasa, yaitu $60 \%$ karena tidak begitu baik dalam mengungkapkan instruksi konseptual dengan bahasan yang baik. Setelah diperbaiki sesuai dengan saran ahli, skor untuk penggunaan bahasa diperoleh $85 \%$.

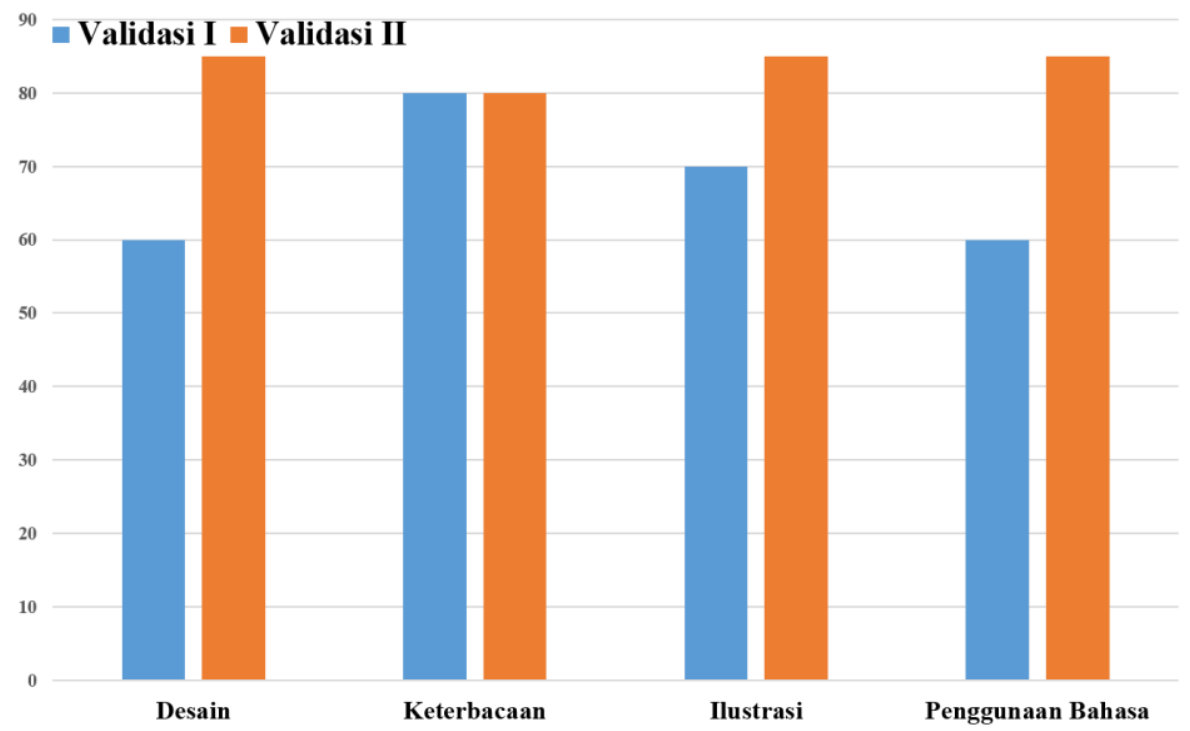

Gambar 3. Hasil Validasi Ahli Media (Interface) Tahap 1 dan 2

Aspek desain pada tahap I mendapatkan skor sebesar $60 \%$, aspek keterbacaan mendapatkan skor sebesar $80 \%$, dan aspek ilustrasi mendapatkan skor $70 \%$. Perbaikan terhadap aspek desain terkait dengan tidak kontrasnya pemilihan warna dan tata letak sedangkan perbaikan pada aspek ilustrasi yaitu terkait dengan pemilihan gambar yang digunakan untuk mengilustrasikan kegiatan. Setelah diperbaiki sesuai saran, dan kemudian di 


\section{validasi kembali, aspek desain ilustrasi mendapatkan skor $85 \%$. mendapatkan skor $85 \%$ dan aspek}

Tabel 3. Saran Perbaikan Ahli Media Tahap 1 dan2

\begin{tabular}{lll}
\hline & \multicolumn{1}{c}{ Saran Perbaikan Media Tahap 1 } \\
\hline & a. & Desain isi modul yang harus sesuai dan seirama, terletak pada \\
& hiasan. \\
& b. & Konsisten dalam penggunaan kalimat. \\
c. Jangan terlalu banyak menggunakan warna pada cover. & d. & Perbaiki EYD dan spasi \\
& e. & Perbaiki penggunaan bahasa, karena masih rancu, susah \\
& f. & Perbahami pembaca \\
& g. & Perbaiki pengunaan kalimat. \\
& h. & Berikan kalimat penghubung pada bagian-bagian tertentu \\
& a. & Perbaiki penulisan kata \\
\hline & b. & Perbaiki cover modul agar tidak mengganggu pemahaman istilah Perbaiki ketepatan ejaan yang \\
& digunakan(harus sesuai EYD)
\end{tabular}

\begin{tabular}{ll}
\hline & Saran Perbaikan Media Tahap 2 \\
\hline AM 1 & Produk sudah bisa diujicoba ke tahap selanjutnya \\
\hline AM 2 & Produk sudah bisa diujicoba ke tahap selanjutnya \\
\hline
\end{tabular}

Produk yang telah melalui tahap validasi dari aspek isi dan antarmuka disajikan pada Gambar 4, Gambar 5, dan Gambar 6.
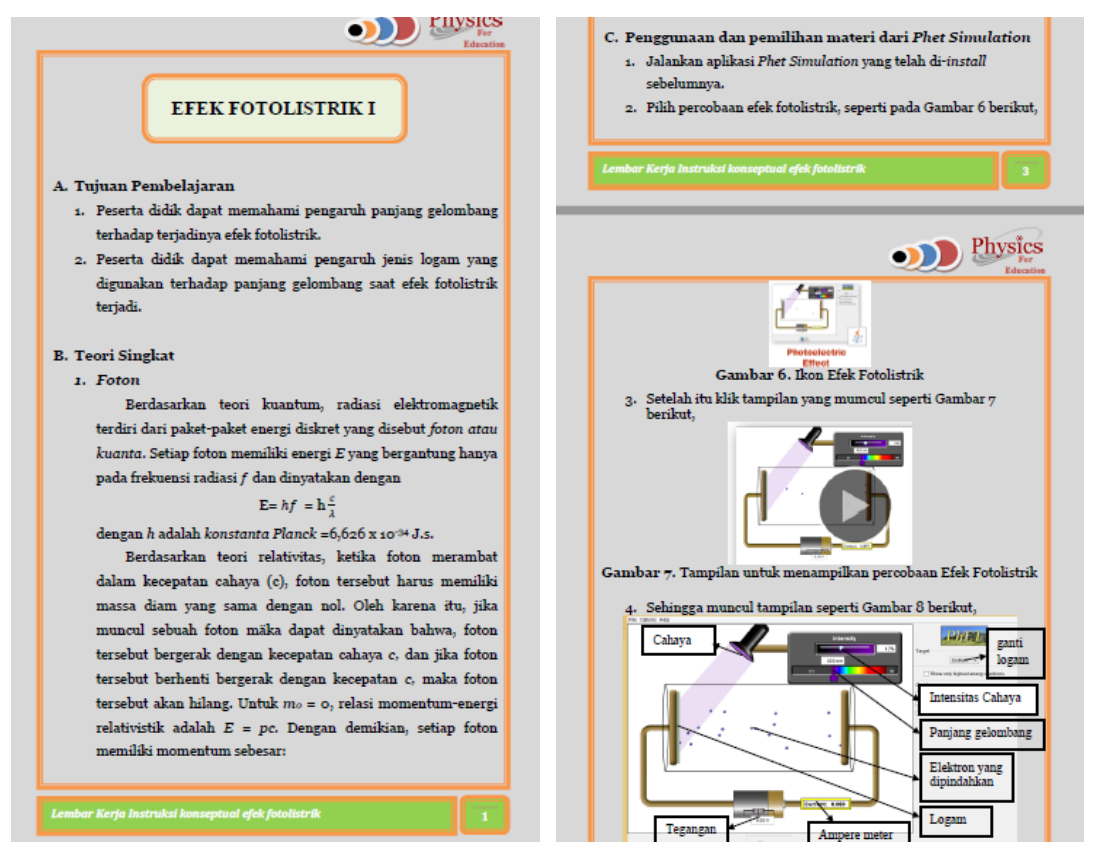

Gambar 4. Bagian Tujuan Pembelajaran, Teori Singkat, dan Penggunaan PhET 

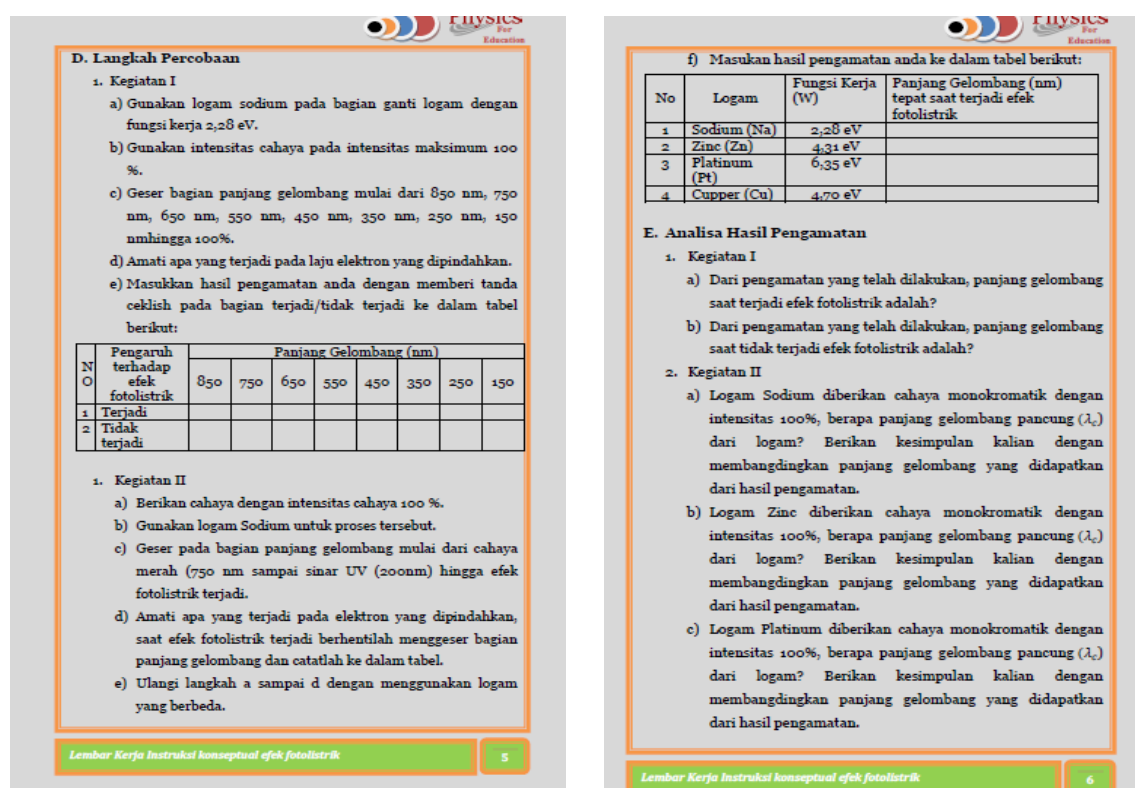

Gambar 5. Bagian Langkah Percobaan dan Analisa Pengamatan

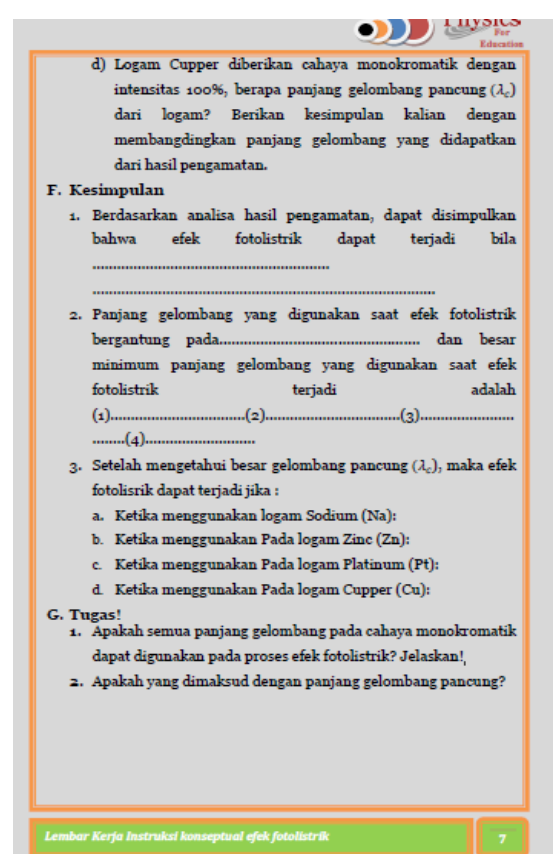

Gambar 6. Bagian Penyusun Kesimpulan dan Tugas

Tahapan terakhir dari penelitian ini adalah Assesment phase. Produk dievaluasi oleh pengguna untuk mengetahui pendapat mereka tentang produk dengan cara respons produk (Sumintono \& Widhiarso, 2015).
Data hasil respon produk oleh pengguna aspek kemenarikan disajikan pada Gambar 7 dan pada aspek kepraktisan disajikan pada Gambar 8. 


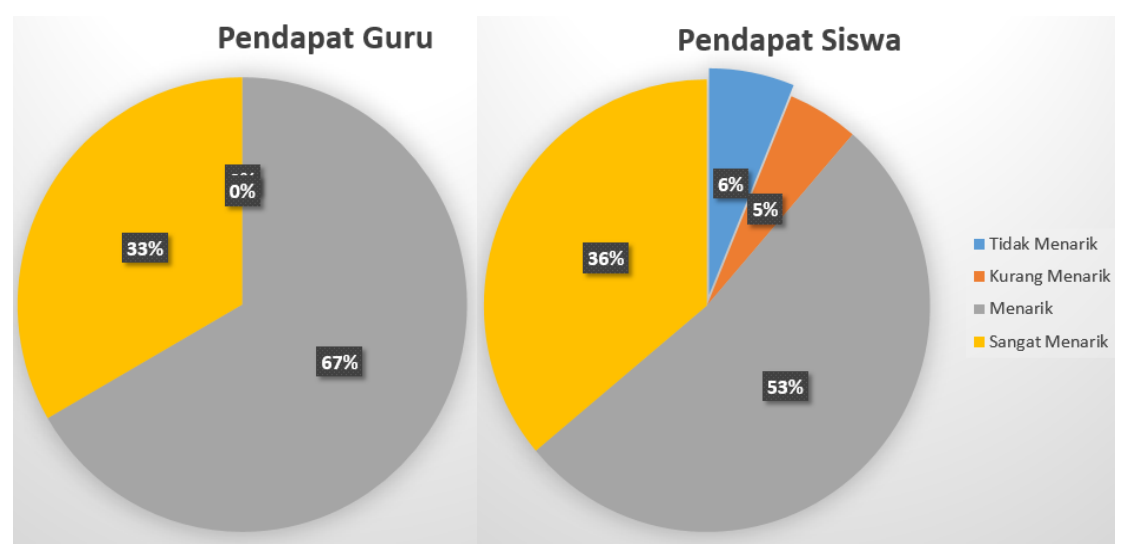

Gambar 7. Pendapat Guru (n=6) dan Siswa $(n=97)$ aspek Kemenarikan

Dari hasil respons produk pada aspek kemenarikan, diketahui bahwa sebanyak 4 orang guru fisika atau sekitar 67\% memberi pendapat produk menarik dan sebanyak 2 orang atau sekitar $33 \%$ sangat menarik, sebanyak 6 siswa atau sekitar $6 \%$ tidak menarik, 5 orang siswa (5\%) kurang menarik, 51 orang siswa $(53 \%)$ menarik, dan sebanyak 35 orang siswa $(35 \%)$ sangat tertarik.

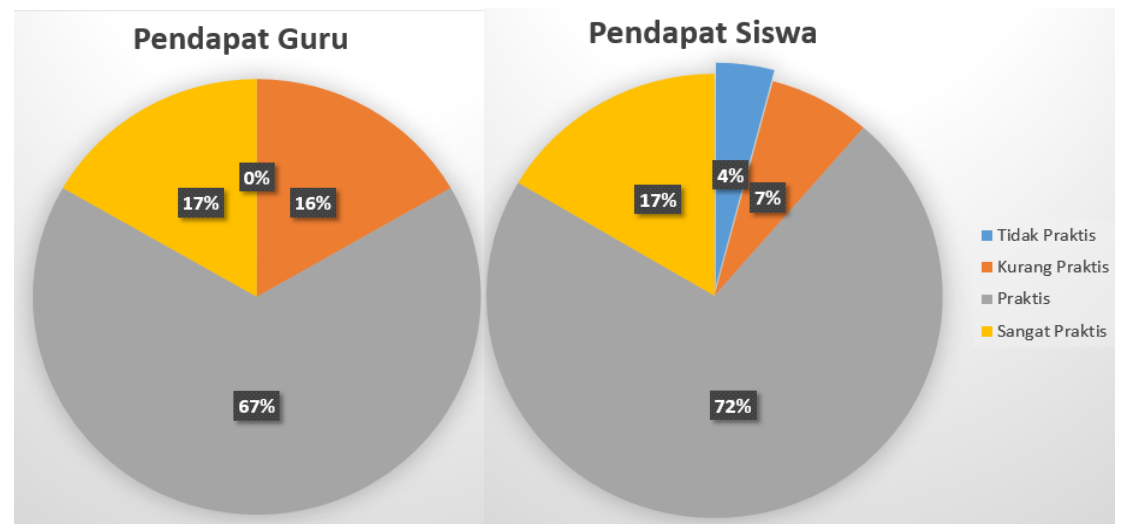

Gambar 8. Pendapat Guru (n=6) dan Siswa (n=97) aspek Kepraktisan

Dari hasil respons produk pada aspek kepraktisan, diketahui bahwa sebanyak 1 orang guru fisika (16\%) berpendapat produk kurang praktis, 4 orang $(67 \%)$ praktis, dan sebanyak 1 guru (16\%) sangat praktis. Pendapat siswa; sebanyak 4 orang (4\%) berpendapat tidak praktis, 7 orang (7\%) kurang praktis, 70 orang $(72 \%)$ praktis, dan 16 orang siswa $(17 \%)$ berpendapat produk sangat praktis.

\section{SIMPULAN DAN SARAN Simpulan}

Berdasarkan tujuan dari penelitian (design research) ini, dapat disimpulkan bahwa produk berupa lembar kerja instruksi konseptual pada materi efek fotolistrik telah dikembangkan dengan baik serta mendapatkan respons oleh guru dan siswa dengan kriteria menarik dan praktis.

\section{Saran}

Produk yang dikembangkan telah tervalidasi baik pada aspek isi dan juga antarmuka, selain itu telah mendapatkan respons yang baik dari aspek kemenarikan dan kepraktisan. Maka, saya menyarankan agar penelitian selanjutnya berkenan untuk melanjutkan penelitian ini sehingga efektivitas produk dapat diketahui.

\section{DAFTAR PUSTAKA}

Adams, W. K. (2010). Student Engagement and Learning with PhET Interactive Simulation. Il 
Nuovo Cimento, 1-12. doi:10.1393/ncc/i2010-10623-0

Astra, I. M., Nasbey, H., \& Nugraha, A. (2015). Development of an Android Application in the Form of a Simulation Lab as Learning Media for Senior High School Students. Eurasia Journal of Mathematics, Science \& Technology Education, 11(5), 1081-1088. doi:10.12973/eurasia.2015.1376a

Asyhari, A., \& Hartati, R. (2015). Implementasi Pembelajaran Fisika SMA Berbasis Inkuiri Terbimbing Terintegrasi Pendidikan Karakter untuk Meningkatkan Hasil Belajar Siswa pada Materi Cahaya dan Optika. Jurnal Ilmiah Pendidikan Fisika 'Al-Biruni', 4(1), 37-49.

Asyhari, A., Sunarno, W., \& Sarwanto. (2014). Pengembangan Perangkat Pembelajaran Fisika SMA Berbasis Inkuiri Terbimbing Terintegrasi Pendidikan Karakter. Jurnal Inkuiri, 3(1), 62-75.

Chen, S., Lo, H.-C., Lin, J.-W., Liang, J.-C., Chang, H.-Y., Hwang, F.K., . . . Tsai, C.-C. (2012). Development and implications of technology in reform-based physics laboratories. Physical Review Special Topics - Physics Education Research, 8(020113), 020113.1-020113.12. doi:10.1103/PhysRevSTPER.8.0 20113

Dede, C., Salzman, M. C., Loftin, R. B., \& Sprague, D. (1999). Multisensory immersion as a modeling environment for learning complex scientific concepts. In W. Feurzeig \& N. Roberts (Eds), Modeling and simulation in science and mathematics education, 282-319. doi:10.1007/978-1-4612-14144_12

Ekmekci, A., \& Gulacar, O. (2015). A Case Study for Comparing the Effectiveness of a Computer Simulation and a Hands-On Activity on Learning Electric Circuits. Eurasia Journal of Mathematics, Science \& Technology Education, 11(4), 765-775. doi:10.12973/eurasia.2015.1438a

Garrett, M., \& McMahon, M. (2013). Indirect measures of learning transfer between real and virtual environments. Australasian Journal of Educational Technology, 29(6), 806-822.

McKagan, S. B., Perkins, K. K., Dubson, M., Malley, C., Reid, S., LeMaster, R., \& Wieman, C. E. (2008). Developing and Researching PhET simulations for Teaching Quantum Mechanics. Boulder: University of Colorado.

Mursalin. (2013). Model Remidiasi Miskonsepsi Materi Rangkaian Listrik dengan Pendekatan Simulasi PhET. Jurnal Pendidikan Fisika Indonesia(2012), 1-7.

Perkins, K., Adams, W., Dubson, M., Finkelstein, N., Reid, S., Wieman, C., \& LeMaster, R. (2006). PhET: Interactive Simulations for Teaching and Learning Physics. The Physics Teacher, 44, 18-23. doi:10.1119/1.2150754

Plomp, T. (2007). Educational Design Research: an Introduction. Dalam T. Plomp, \& N. Nieveen (Penyunt.), Curriculum Development Conference (hal. 935). SLO Netherlands institute for curriculum development.

Podolefsky, N. S., Perkins, K. K., \& Adams, W. K. (2010). Factors 
promoting engaged exploration with computer simulations. Physical Review Special Topics Physics Education Research, 6(020117), 020117.1-020117.11. doi:10.1103/PhysRevSTPER.6.0 20117

Saregar, A. (2016). Pembelajaran Pengantar Fisika Kuantum dengan Memanfaatkan Media PhET Simulation dan LKM Melalui Pendekatan Saintifik: Dampak Pada Minat dan Penguasaan Konsep Mahasiswa. Jurnal Ilmiah Pendidikan Fisika 'Al-BiRuNi', 5(1), 53-60.

Savinainen, A., \& Viiri, J. (2008). The Force Concept Inventory as a Measure of Students Conceptual Coherence. International Journal of Science and Mathematics Education, 6(4), 719-740. doi:10.1007/s10763-007-9103-x

Setiadi, R., \& Muflika, A. A. (2012). Eksplorasi Pemberdayaan Courseware simulasi PhET untuk membangun Keterampilan Proses Sains SIswa SMA. Jurnal Pengajaran MIPA, 17(2), 258268.

Suhandi, A., Sinaga, P., Kaniawati, I., \& Suhendi, E. (2009). Efektifitas Penggunaan Media Simulasi Virtual pada Pendekatan Pembelajaran Konseptual Interaktif dalam Meningkatkan Pemahaman Konsep dan Meminimalkan Miskonsepsi. Jurnal Pengajaran MIPA, 13(1), 35-47.

Sumargo, E., \& Yuanita, L. (2014). Penerapan Media Laboratorium Virtual (PhET) Pada Materi Laju Reaksi dengan Model Pengajaran Langsung. Unesa Journal of Chemical Education, 3(1), 119133.

Sumintono, B., \& Widhiarso, W. (2015). Aplikasi Pemodelan Rasch: pada
Assessment Pendidikan.

Bandung: Trim Komunikata.

Wademan, M. (2005). Utilizing Development Research to Guide People Capability Maturity Model Adoption Considerations. New York: Unpublished doctoral dissertation.

Waller, J. C., \& Foster, N. (2000). Training via the web: A virtual instrument. Computer Education, 35(2), 161-173.

Wang, Q., \& Woo, H. L. (2007). Systematic Planning for ICT Integration in Topic Learning. Educational Technology \& Society, 10(1), 148-156.

Wegener, M., McIntyre, T. J., \& McGrath, D. (2012). Developing a virtual physics world. Australasian Journal of Educational Technology, 28(3), 504-521.

Wieman, C. E., K, K., Perkins, \& Adams, W. K. (2008). Oersted Medal Lecture 2007: Interactive Simulation for Teaching Physics: What Works, What doesn't, and why. American Journal of Physics, 76(4), 393-399. doi:10.1119/1.2815365 